Wenner, D.M. (2014). “Against Permitted Exploitaiton in Developing World

Research Agreements,” Developing World Bioethics, doi: 10.1111/dewb.12081 (epub ahead of print).

This is a pre-print of a published manuscript. When citing, please refer to the final, published version at http://onlinelibrary.wiley.com/doi/10.1111/dewb.12081/abstract

Address correspondence to:

Danielle M. Wenner

Department of Philosophy, Carnegie Mellon University

155C Baker Hall, Pittsburgh, PA 15213

Telephone 412-268-8046

FAX 412-268-1440

dwenner@andrew.cmu.edu 


\section{Against Permitted Exploitation in Developing World Research Agreements}

Debates about clinical research conducted in lower- and middle-income countries

(LMICs) have focused largely on the question of exploitation: how to define it, and

how best to avoid it. ${ }^{1}$ Questions concerning what is owed to research participants in exchange for participation, access to treatments after a trial's conclusion, and what constitutes an appropriate standard of care can all usefully be viewed as striving to protect subjects and host communities from exploitation.

Such discussions are stymied by ongoing entrenched disagreement at the theoretical level regarding the normative content of the moral wrong of exploitation. ${ }^{2}$ Despite this theoretical disagreement, most contemporary theorists agree that the most interesting and difficult to characterize class of wrongfully exploitative interactions are those which are both fully consensual as well as beneficial to all parties involved. For example, sweatshop labor is often cited as paradigmatic of exploitation, but labor agreements in LMICs can look procedurally fair: laborers and employers both offer valid consent to the transactions, and both appear to benefit employers from drastically reduced overheads, and employees from wages and working conditions which, although inadequate from the perspective of those in highincome settings, are better than the alternatives locally available. The charge of

\footnotetext{
${ }^{1}$ E.J. Emanuel, et al. What makes clinical research in developing countries ethical? The benchmarks of ethical research. J Infect Dis 2004; 189:930-7; A.J. London. Justice and the Human Development Approach to International Research. Hastings Cent Rep 2005; 35:24-37; T. Pogge. 2008. Testing Our Drugs on the Poor Abroad. In Exploitation and Developing Countries: The Ethics of Clinical Research, Hawkins and Emanuel, ed. Princeton: Princeton University Press: 105-141; A. Wertheimer. 2011. Rethinking the Ethics of Clinical Research: Widening the Lens. Oxford: Oxford University Press.

${ }^{2}$ A. Wertheimer. 1996. Exploitation. Princeton: Princeton University Press; R. Sample. 2003. Exploitation: What It Is and Why It's Wrong. New York: Rowman \& Littlefiel; M. Valdman. A Theory of Wrongful Exploitation. Philosopher's Imprint 2009; 9:1-1; R.W. Miller. 2010. Globalizing Justice. Oxford: Oxford University Pres; A.W. Wood. Exploitation. Soc Philos Policy 1995; 12:136-15; R.E. Goodin. 1987. Exploiting a Situation and Exploiting a Person. In Modern Theories of Exploitation, Reeve, ed. Beverly Hills: SAGE Publications: 166-200.
} 
wrongful exploitation therefore seems to refer to the fairness of the distribution of the social surplus of a transaction, or to some other feature, but not to its procedural fairness.

Controversial cases of clinical research conducted in LMICs can share these same characteristics: research sponsors need not deceive or manipulate host communities into participating in research. And host communities and trial participants can benefit relative to their pre-transaction baseline: by receiving medical care they otherwise could not access, increased local healthcare capacity, or other compensation. Nevertheless, many feel an intuitive discomfort with some subset of clinical trials conducted in LMICs, and argue that they are wrongfully exploitative and therefore should not be permitted. ${ }^{3}$

While questions regarding what constitutes exploitation in international clinical research are important, this paper addresses a different question about the ethics of research conducted in LMICs: Suppose it is the case that some international research transactions are wrongfully exploitative. Would this imply that a third party would be morally justified in enforcing substantive limits to the outcomes of those transactions? The answer to this question may actually be prior: If, as policy-makers and bioethicists have suggested, the answer to this question is "no"; that a third party would not be morally justified in imposing limits on otherwise procedurally fair exploitative research agreements, then debates about the normative content of exploitation in international clinical research would become less urgent, because of less practical import.

\footnotetext{
${ }^{3}$ Cf. Pogge, op. cit. note 1.
} 
I argue that, in fact, this answer is wrong. In particular, I show that defenders of the claim that interference with mutually beneficial exploitative research transactions is unjustified - whom I call "liberals about exploitation" - rely on the primacy of individual autonomy and the empirical claim that interfering with international research transactions will ultimately deprive host communities of goods which they desperately need. The central claim of this paper is that the case for these beliefs rests on a mischaracterization of certain forms of interference as paternalistic and two dubious empirical assumptions about the results of regulation. The view I put forward is that by evaluating a system of constraints on the outcomes of international research agreements rather than individual instances of interference, we can better assess the alternatives to permitting exploitative research arrangements. While I do not address the permissibility of individual instances of mutually beneficial exploitation under non-ideal conditions, I do suggest that the predominant focus of contemporary debates about exploitation on so-called "transaction-specific fairness" is misplaced to the extent that conclusions about interference with individual transactions are leveraged in support of what often boils down to a laissezfaire approach to regulation. Rather than debating the legitimacy of ad hoc intercessions in, or the prohibition of, individual clinical trials, research ethicists should focus their attention on the kinds of institutional reforms necessary to ensure a fairer distribution of the benefits generated by international research.

This paper focuses specifically on clinical pharmaceutical research (aimed at the development of new drugs or vaccines) conducted in LMICs but funded by external industry or non-profit sponsors (either directly or indirectly through contract 
research organizations). The regulation of clinical research which is wholly internally sponsored is therefore outside of the scope of this analysis. Whether effective constraints can be instituted which instantiate the kinds of limits I suggest is itself an empirical question, and I conclude with the recommendation that an exploration of the options available for better regulating the terms of international research transactions be undertaken. In this discussion, I follow those with whom I am engaging and take it for granted that a transaction which is procedurally fair may nevertheless be exploitative or unfair in terms of its substance, and that at least some international research fits this description.

\section{The Defense of Non-Intervention}

Arguments for non-interference with mutually-beneficial, exploitative research transactions are grounded in two related claims. First, it is argued that the practical upshot of interference with such transactions is to deprive very needy communities of benefits to which they otherwise lack access. Second, interference with such interactions is argued to constitute a violation of individual autonomy and community self-determination, and therefore an unjustified form of paternalism.

Thus, defenders of the "Fair Benefits" approach to justice in international research argue that, "the determination of whether the benefits are fair and worth the risks cannot be entrusted to people outside the population, no matter how well intentioned"4 and that:

[R]equiring [specific benefits] tacitly suggests that the population cannot make its own, autonomous decisions about what benefits are worth the risks

\footnotetext{
${ }^{4}$ Participants in the 2001 Conference on Ethical Aspects of Research in Developing Countries. Fair Benefits for Research in Developing Countries. Science 2002; 298:2133-2134: 2134.
} 
of a research trial... Disregarding the community's view about what constitutes appropriate benefits for them - insisting that a population must benefit in a specific manner - implies a kind of paternalism. ${ }^{5}$

In a similar vein, Alan Wertheimer defends what he calls the "Permitted Exploitation Principle” (PEP), which states that if an otherwise exploitative transaction between A (exploiter) and B (exploited) will serve B's interests, all things considered, if the transaction will not harm anyone external to the transaction, and if B makes a voluntary, informed, and rational decision to transact with A, then it would be wrong to interfere with such a transaction. Note that Wertheimer is not making a claim about the ethics of the transaction itself: he is not claiming that it is morally permissible for A to exploit B. Rather, he is making the more limited claim that regardless of the (im)morality of exploitation, "it is wrong to prevent Pareto superior or win-win transactions on the grounds that the terms of such transactions are unfair. The PEP refers to the morality of regulating transactions, and not the morality of transactions themselves". ${ }^{6}$ Here again, the operant conditions in the defense of the PEP are the voluntariness of the transaction, and the resultant benefits to both parties (most notably, the exploited party).

I take the PEP as paradigmatic of the position defended by liberals about exploitation in clinical research, and it is to such defenders that my arguments are directed. Specifically, I demonstrate that systematic interference with mutually beneficial but exploitative research agreements could generate greater benefits for

\footnotetext{
${ }^{5}$ Participants in the 2001 Conference on Ethical Aspects of Research in Developing Countries. Moral Standards for Research in Developing Countries: From "Reasonable Availability" to "Fair Benefits". Hastings Cent Rep 2004; 34:17-27: 21.

${ }^{6}$ Wertheimer, op. cit. note 1: 218-9.
} 
host communities and trial participants without disrespecting their self-determination, and that absent additional countervailing reasons, such restrictions are therefore justifiable.

\section{Autonomy \& Paternalism}

Liberals about exploitation are greatly concerned that substantive restrictions on the outcomes of research negotiations would constitute unjustified interference with community autonomy ${ }^{7}$, and therefore a form of impermissible paternalism. If the following arguments are correct, however, such liberals are confused: they want to prevent paternalistic interference in order to better realize precisely the goal of that interference. There is an interesting tension in defending the permissibility of exploitation for the benefit of the party being exploited while maintaining the impermissibility of paternalistic interference designed to provide even greater benefits of the same form.

More to the point, we might ask what, precisely, the content of the complaint is. The charge of paternalism implies that constraints are imposed which function to undermine the ability of the intended beneficiaries to pursue their own values. But there are instances in which the coercive imposition of limits to actions or interactions is necessary to ensure that individuals are able to pursue their interests as endorsed as such by those individuals. Specifically, many coordination problems require restrictions intended to promote the interests of a group of individuals in those

\footnotetext{
${ }^{7}$ The notion of "community autonomy" is not unproblematic, but unpacking this concept is outside the scope of this paper. For my purposes, "community autonomy" can be considered a heuristic for the autonomy of individual members of a community and the community-wide self-determination which is comprised of some form of local consultation process that allows the community to make reasonable decisions regarding public policy. For a more substantive account of community autonomy, see C.H. Wellman. The Paradox of Group Autonomy. Soc Philos Policy 2003; 20:265-285.
} 
instances when, absent some mechanism for ensuring the cooperation of others in the group, individual members have reason to default. In such instances, the interests of each member of the group are furthered by the restriction of her own as well as each other member's actions. ${ }^{8}$

Thinking about international research transactions in terms of a collective action problem is instructive. Communities operate in a market condition of scarcity, with limited opportunities to access basic healthcare or expensive infrastructure. Conversely, global research sponsors operate in a market condition of surplus, with many populations without access to basic medical care eager to attract resources to their communities. Faced with this reality, host communities are essentially in competition with one another to provide a viable research setting and trial participants to foreign sponsors or contract research organizations (CROs) for the lowest cost possible. $^{9}$ Any uncoordinated attempt to raise the cost on the part of an individual community will result in another community attracting the research away. This is precisely the concern enunciated by liberals about exploitation when they worry that interference with research transactions will deprive host communities of benefits.

But as in other collective action problems, this concern only manifests when considering unilateral action on the part of an individual community, or interference with only isolated instances of exploitative research. A useful analogy is a minimum wage: absent a guarantee that others won’t work for less, individual laborers face constant downward pressure on their wages, regardless of the value they ascribe to their work. But the presence of an enforcement mechanism functions to coordinate

\footnotetext{
${ }^{8}$ G. Dworkin. Paternalism. Monist 1972; 56:64-84.

${ }_{9}^{9}$ A.J. London and K.J.S. Zollman. Research at the Auction Block: Problems for the Fair Benefits Approach to International Research. Hastings Cent Rep 2010; 40:34-45.
} 
the efforts of laborers, and results in higher pay for all. Any institutional mechanism capable of governing only some limited portion of international research transactions would have the counterproductive effect of removing benefits from only those populations bound by the governance. But insofar as a mechanism could be established which functioned to successfully limit the outcomes of all, or at least a substantial portion of, research negotiations, the collective action problem could be resolved in a manner which supports the autonomous interests of host communities, rather than imposing some conception of the good on them to which they may or may not ascribe.

It is not only the case that a broadly applicable system of regulation will benefit those communities who would likely host research. The universality of such a mechanism is also to the benefit of research sponsors and CROs. If it is the case that a moral principle of non-exploitation demands that better terms are offered to participants and host communities, any party seeking to meet this obligation on its own would do so in the context of competitors not similarly inclined, and face the very real prospect of fair transacting its way right out of business. Some take this to imply that such a moral principle could not require potential exploiters to unilaterally transact more fairly. ${ }^{10}$ Even if we reject this claim, however, it seems unlikely that individual research sponsors or CROs would act on such a moral obligation absent some form of assurance that others will not be capable of putting them out of business simply by offering potential host communities and trial participants less fair terms. This provides additional motivation for such a system to be implemented in a manner

\footnotetext{
${ }^{10}$ Miller, op. cit. note 2: 66-7.
} 
that governs all - or at least a clearly defined subset - of international research transactions.

One way to envision the kind of system required is policy enacted at the global level, governing all transactions occurring between pharmaceutical companies, CROs, state agencies, or NGOs and localities seeking to host externally-sponsored research. Ideally, such a system could be established through international trade policies with the support of governance bodies such as the World Trade Organization (WTO). But while this may be the most effective means of regulating international research transactions, it is by no means the only avenue available. Significant progress could be made in this direction if regulatory bodies in the largest pharmaceutical markets, and specifically the US and EU, were to strengthen existing regulations for the prospective registration of trials and comprehensive data submission. These agencies could then utilize their authority to limit market access to enforce more substantive restrictions on the amount of benefits required to accrue to populations hosting trials that are then used to support marketing applications. Given the pharmaceutical market share represented by these high-income markets, even such piecemeal regulation at the state-level would retain the ability to capture the vast majority of trials by aligning the market-based incentives of drug manufacturers with the desire to protect LMIC communities from exploitation.

It also need not be the case that any mechanism to limit the outcomes of research negotiations be entirely, or even largely, externally-imposed. Likely host communities, and LMIC nations more broadly, can and should be engaged and fully empowered in the process of determining the best policy and oversight mechanisms 
for ensuring fair distributions of research-generated benefits. Such engagement can be construed as an additional means of promoting the autonomy of communities, further undermining the claim that any substantive limitation to research transactions must constitute unjustified paternalism. We might extend the labor analogy and envisage a partnership among host communities resembling a labor union - working together both to promote each other's interests, as well as to ensure that no individual community is undercutting the others by accepting research agreements which don't meet the criteria established. Such decision-making could also conceivably involve research sponsors themselves, who could shed light on the types and kinds of limitations to research transactions which are likely to be feasible from an economic standpoint.

Liberals about exploitation might object that nothing within their perspective implies that potential host communities ought not work together to reach an agreement regarding the kinds of research transactions they will accept. However this reply ignores important facts about the context within which such efforts must be made. First, those potential host communities who are most vulnerable to exploitation by research sponsors are unlikely to be in an economic position to coordinate such efforts with other communities similarly situated. The development of multilateral trade agreements or new marketing restrictions in the largest markets will be costly, time-consuming, and require input from stakeholders to whom community members may not have direct access. Facilitation of such regulation by state-level officials, research sponsors, and/or international bodies will likely be necessary. 
Second, potential host communities are also unlikely to be well-positioned to enforce the provisions of any such agreement. While host community involvement in determining the appropriate structure and content of research regulation is one way to ensure that communities are empowered to determine the level of recompense considered reasonable for all, the cooperation of external parties will be necessary to ensure that such an agreement is abided by and enforced. Global governance bodies such as the WTO are better positioned to enforce penalties for the violation of multilateral trade agreements, while regulatory agencies within high-income markets are well-situated to use their gatekeeping function to ensure that the trials being leveraged in support of marketing applications are being conducted on fair terms.

Finally, to assume that potential host communities could organize, produce, and establish enforcement mechanisms to regulate international research transactions independently of third parties fails to take seriously the situatedness of such agreements within the global economic system. The focus of contemporary debates about exploitation on so-called "transaction-specific fairness" and the role of individual choice in negotiations obscures the background relationships which significantly determine the choices available to all parties involved. Global trade, and specifically international research transactions, occurs within a complex system of global governance in which policies are dictated largely by organizations whose processes are non-transparent and undemocratic. ${ }^{11}$ The way in which power asymmetries are utilized in global trade negotiations clearly illustrates the lack of self-determination afforded to lower- and middle-income communities in the design of the regulatory structures which govern their transaction-level negotiations. To call

\footnotetext{
${ }^{11}$ J. Stiglitz. 2006. Making Globalization Work. New York: W. W. Norton \& Company.
} 
the introduction of new regulatory structures designed to help communities protect their interests "paternalistic" is to miss the point entirely. Promoting substantive limits to the outcomes of research transactions is one way to empower host communities within a global institutional context which largely functions to remove from them the ability to protect their interests.

Perhaps the largest concern regarding such a mechanism is analogous to an objection often levied against minimum wage laws: they're counterproductive. The upshot is to deprive workers of goods, since employers will not hire them if they cannot afford the wages, with the result that fewer individuals will be employed. This same concern is the basis for the worries expressed by liberals about exploitation; that restrictions on research transactions will have the desultory effect of removing opportunities for communities to benefit from international research.

What I have argued so far could be considered a version of what Wertheimer refers to as "the strategic argument" for interference with mutually beneficial exploitative transactions. ${ }^{12}$ Perhaps the most sympathetic of liberals about exploitation to the possibility of legitimate interference with international research transactions, Wertheimer appears to agree that regulatory interference need not violate the autonomy of the potentially exploited. But he ultimately remains agnostic regarding the strength of the strategic argument as it applies to international clinical research, and concludes that it is an empirical question whether regulatory interference with such transactions would or could actually help prospective subjects or host communities, or would have the contrary effect of ultimately depriving them

${ }^{12}$ Wertheimer, op. cit. note 2: 300-5. 
of much-needed benefits. ${ }^{13}$ The rest of this paper can thus be construed as an empirically-informed defense of the claim that international research transactions could be limited at the regulatory level without having the detrimental effects on host communities which liberals about exploitation predict.

\section{The Concern for Benefits}

I have so far argued that the case in favor of liberalism about exploitation is predicated on a desire to preserve the autonomy of potential trial participants and host communities, as well as the observation that interfering with mutually beneficial exploitation will have the result of denying benefits to needy populations. I have shown that a systematic implementation of restrictions to research negotiations need not undermine host community autonomy. Here I will address the second claim, that such interference will deprive LMIC populations of much-needed benefits. The case for this second claim rests on an important separate premise, which is that the exploiting party is under no moral obligation to transact with the exploited party: if the costs of doing business in LMIC communities were to increase due to substantive constraints on the outcomes of research negotiations, then it would be morally permissible for sponsors to choose not to conduct their trials in such settings, and to thereby deprive communities of the opportunity to benefit from such transactions.

One way to dispute liberals about exploitation is therefore to reject the claim that global research sponsors are not ethically obligated to conduct research in underprivileged populations. While generally sympathetic to this charge, or at least to the closely related claim that sponsors are obligated to conduct research the results of which are intended to benefit underprivileged populations, this is not a line of

\footnotetext{
${ }^{13}$ Wertheimer, op. cit. note 1: 216-7.
} 
argument which I here pursue. Rather, I take it for granted, along with liberals about exploitation, that global research sponsors are under no imperative to conduct research in LMIC settings, and that there is at least prima facie reason to maintain the financial incentive for them to do so if doing so ensures otherwise unavailable benefits to very needy populations.

But to both accept that the exploiting party has no obligation to transact with the exploited party while rejecting calls for non-interference seems to commit us to the claim that it can be morally worse for A to interact with B in a manner which is beneficial to $\mathrm{B}$ and to which $\mathrm{B}$ consents than to not interact with $\mathrm{B}$ at all, and that we may have an obligation to stop such apparently beneficial interactions from taking place. ${ }^{14}$ It is the seemingly puzzling nature of these commitments which motivates the liberal's defense of non-interference and the intuitive pull of the PEP.

Even accepting the permissibility of non-interaction, however, a defense of non-interference with exploitative international research hinges on the veracity of two additional, empirical claims: that we can't increase what is due to host populations without removing the incentive to do research in these communities (what I refer to as "the incentives claim"), and the related claim that the sum of resources available for clinical research is fixed (what I refer to as "the fixed resources claim”).

The incentives claim is at the heart of the argument that interference with such transactions would deprive communities of resources which they desperately need and the case for this claim is at least initially plausible. Take, for example, the wellknown Surfaxin trials in which Discovery Labs sought to test a drug for the treatment of infant respiratory distress syndrome (RDS), a life-threatening condition for which

\footnotetext{
${ }^{14}$ Ibid. 256-7.
} 
there were already several established effective interventions available in highincome markets. Worried about their ability to demonstrate superiority in an activecontrolled trial, and informed by the FDA that a non-inferiority trial would not suffice for a marketing application, Discovery Labs planned to test their drug against placebo in Latin America, where Surfaxin was unlikely to ever be marketed given its high price. ${ }^{15}$ Pursuant to the controversy that was generated about this trial, however, Discovery Labs eventually re-designed the trial to include an active comparator, and conducted it in high-income markets instead. The result was that the initiallyintended host communities never received the medical infrastructure and training which was part of the research agreement, and none of the infants in those communities who contracted RDS ever received Surfaxin.

While it is true that the result of the Surfaxin trial re-design was a loss of benefits to the intended host communities, this is proof not that substantive restrictions on the outcomes of research transactions necessarily lead to the diversion of such resources, but rather that any such restrictions must be both implemented systematically, as noted above, as well as designed in such a way as to maintain the incentive to conduct research in LMIC populations. ${ }^{16}$ Conducting research in LMICs in most cases represents a significant cost reduction for international research sponsors. In one comparative analysis, a full program of research for a new TB intervention from Phase I through III was estimated to cost US \$26.6 million in an

\footnotetext{
${ }^{15}$ J.S. Hawkins and E.J. Emanuel. 2008. Case Studies: The Havrix Trial and the Surfaxin Trial. In Exploitation and Developing Countries: The Ethics of Clinical Research, Hawkins and Emanuel, ed. Princeton: Princeton University Press: 55-62.

${ }^{16}$ Angela Ballantyne presents one account of what is due to host communities that seeks to maintain the existing incentives for global research, see A.J. Ballantyne. How to Do Research Fairly in an Unjust World. Am J Bioeth 2010; 10:26-35.
} 
established economy, while a comparable program conducted in a developing economy was estimated at US $\$ 9.9$ million, a greater than $60 \%$ reduction. ${ }^{17}$ Even if this analysis significantly overestimates the differential, it suggests that substantive limits to research transactions need not have the direct effect of depriving communities of ill-needed gains. At a minimum the size of the cost differential provides prima facie reason to reject the incentives claim.

Even if the incentives claim is false, however, this would not preclude the following, indirect effect of demanding fairer research agreements: If the resources available for the conduct of clinical research are fixed, demanding greater benefits for one host community may have the unfortunate consequence of precluding another trial's being conducted at all, thus still preventing some from receiving much-needed benefits. Moreover, implementing systematic restrictions requiring fairer distributions of the social surplus from international research would compound this worry: by increasing the costs associated with conducting clinical trials in LMICs, such regulatory institutions would reduce the number of trials which could be conducted. ${ }^{18}$ Given this concern, we must also interrogate the veracity of the fixed resources claim. With regards to research funded privately by the pharmaceutical industry, the claim is at best dubious. The pharmaceutical industry is a multi-billion dollar enterprise which is eight times more profitable than the average of all other industries represented on the Fortune 500 list. $^{19}$ Although the industry has widely

\footnotetext{
${ }^{17}$ Global Alliance for TB Drug Development. 2001. Executive Summary for the Economics of TB Drug Development. Estimates do not include costs related to probability of failure.

${ }^{18}$ A. Wertheimer, J. Millum and G.O. Schaefer. Why Adopt a Maximin Theory of Exploitation? Am J Bioeth 2010; 10:38-39.

${ }^{19}$ S. Sterckx. Patents and Access to Drugs in Developing Countries: An Ethical Analysis. Dev World Bioeth 2004; 4:58-75.
} 
cited the costs of R\&D for each new drug to be upwards of US $\$ 800$ million, ${ }^{20}$ there is reason to believe that this figure has been grossly over-inflated. A recent analysis of research and development costs demonstrated that the mean and median costs associated with the development of new drugs are closer to US \$60 million and \$45 million, respectively. ${ }^{21}$ Given the centrality of research to the pharmaceutical business model, there is little reason to think that greater resources would not or could not be invested in maintaining an equally active research profile were there external mechanisms generating increased costs for all.

This concern may be of greater relevance with regard to research funded publicly or through non-profits or NGOs. ${ }^{22}$ Such bodies operate within budgetary constraints which do not apply to the highly profitable pharmaceutical industry, making increased costs more salient. Moreover, this pool of research funding is much more likely to address the needs of underdeveloped populations than the private sector, given the lack of financial incentives for industry to develop interventions for diseases and conditions which disproportionately affect the global poor. ${ }^{23}$ This compounds the concern that by increasing the costs associated with such research, we might remove benefits from needy populations, because it suggests that we also run

\footnotetext{
${ }^{20}$ J.A. DiMasi, R.W. Hansen and H.G. Grabowski. The Price of Innovation: New Estimates of Drug Development Costs. J Health Econ 2003; 22:151-185.

${ }^{21}$ D.W. Light and R. Warburton. Demythologizing the High Costs of Pharmaceutical Research. Biosocieties 2011; 6:34-50. This analysis used the same data set as the original DiMasi study, but was adjusted in three primary ways: (1) It incorporated data from all new pharmaceutical patents, rather than only new chemical entities, which make up fewer than $20 \%$ of new patents, (2) it adjusted for taxpayer subsidies and tax deductions, which the US Office of Technology Assessment has estimated reduce R\&D costs by upwards of $40 \%$, and (3) It reduced the estimated opportunity costs from the Tufts study, which had assumed an $11 \%$ return on capital not spent on R\&D, whereas U.S. federal guidelines recommend an assumed 3\% return on capital investments.

${ }^{22}$ Wertheimer, Millum, \& Schaefer, op. cit. note 18.

${ }^{23}$ S.R. Benatar and C.L. Vaughan. Global and Local Forces Shaping the Research Agenda and the Governance of Research Ethics. S Afr J Sci 2008; 104:439-44; P. Trouiller, et al. Drug Development for Neglected Diseases: A Deficient Market and A Public-Health Policy Failure. Lancet 2002; 359:2188-2194.
} 
the risk of depriving populations of important biomedical advances intended to address their disproportionate level of ill health.

This concern is legitimate, though I worry that it is over-stated, precisely for the reasons given above: non-profits and NGOs operating within LMICs are far more likely to be conducting research on interventions of relevance to local populations, which may already cut against claims of exploitation. Although the precise nature of exploitation claims in trials such as Surfaxin is controversial, the worries with such trials are largely informed by the facts both that the population's lack of access to advanced medicine makes feasible the use of placebo controls or other standards of care which are less costly than those available in higher-income settings, and that the drug being tested may not be intended for marketing or other distribution to the local population after the trial. In short, the host community's unfortunate situation is leveraged in a way that will benefit them very little in comparison to the gains to the research sponsor in generating data to support a marketing application in a highincome market and individuals in that market who will benefit from access to the new intervention. Both the standard of care provided within a trial as well as the distribution of an effective intervention after its conclusion can be construed as significant means by which to funnel a greater share of the social surplus created by a clinical trial to host communities and trial participants. And conversely, failures on the part of sponsors to provide adequate standards of care or access to proven interventions can be construed as specific instances of retaining larger than a fair share of that surplus. 
This reasoning might be extended. The liberal's argument in support of noninterference due to the potential for the deprivation of benefits assumes that the claim of exploitation of international host communities is grounded solely in the amount of benefits offered to participants and communities, but this need not be the sole, or even the main, substance of the complaint. While procedural features of the transactions in question are stipulated to be fair, what is at stake in these instances of exploitation may not be merely a matter of the distribution of the research-generated social surplus - it may also be a matter of what that social surplus consists in. For example, one way in which research conducted in and on LMIC populations may be wrongfully exploitative is when the expected or targeted epistemic gains from the research are not intended to be leveraged in a manner which will directly benefit the host community. On this account, a host community is exploited insofar as it absorbs the risks and burdens associated with clinical research, but does not gain any of the social benefits of biomedical progress which serve to justify exposing research participants to such risks. ${ }^{24}$ Thus in addition to representing a failure on the part of sponsors to fairly distribute the social surplus generated by a clinical trial, conducting research in LMIC populations on interventions which are not intended for local marketing or distribution may constitute a substantive form of exploitation independent of other distributional considerations.

In contrast to research conducted by or for industry sponsors, research sponsored by public or non-profit institutions such as the World Health Organization, the Bill and Melinda Gates Foundation, or the U.S. National Institutes of Health - if

\footnotetext{
${ }^{24}$ D.M. Wenner. The Social Value of Knowledge and International Clinical Research. Dev World Bioeth 2013; epub ahead of print.
} 
being conducted in an LMIC - is far more likely to be targeting the specific health needs of the population hosting the research. For example, the WHO sets research priorities "that meet health needs particularly in low- and middle-income countries", ${ }^{25}$ while $75 \%$ of all of the Gates Foundation's global health spending is devoted to HIV/AIDS, malaria, vaccine-preventable diseases, child health, TB, and other tropical and neglected diseases. ${ }^{26}$ While detailed analyses of which research programs are being pursued where are sadly lacking, ${ }^{27}$ the mandates of such organizations dictate that research address the health needs and priorities of LMIC populations. The same is true for the product development partnerships which are rapidly proliferating as a way of addressing the research gap in neglected tropical diseases. ${ }^{28}$

Moreover, appeal to the local epistemic value of research results need not necessarily remove from consideration the amount of benefits accruing to a host community or the overall distribution of the social surplus from a given trial. Rather, research outputs which are intended to be put to use addressing local health needs and priorities are likely to be longer lasting and ultimately more impactful than one-off exchanges for economic goods or short-term access to medical interventions. Thus even if the charge of wrongful exploitation ultimately does come down to a pure consideration of the fair distribution of the social surplus derived from research, appropriately-targeted research endeavors are more likely to satisfy the criteria for a

\footnotetext{
${ }^{25}$ World Health Organization. 2014 [Last Accessed 2014-08-22 http://www.who.int/topics/research/en/]. ${ }^{26}$ D. McCoy, et al. The Bill \& Melinda Gates Foundation's grant-making programme for global health. Lancet 2009; 373:1645-1653.

${ }^{27}$ D. Sridhar and R. Batniji. Misfinancing global heatlh: a case for transparency in disbursements and decision making. Ibid.2008; 372:1185-1191.

${ }^{28}$ S. Moon, J. Bermudez and E.t. Hoen. Innovation and Access to Medicines for Neglected Populations: Could a Treaty Address a Broken Pharmaceutical R\&D System? PLoS Med 2012; 9:e1001218.
} 
"fair" or "non-exploitative" distribution. Given that non-profit research sponsors are more likely to be conducting research of local epistemic relevance, concerns about opportunity costs are suddenly less severe: intervening to prevent exploitative research transactions may only significantly impact the types and amounts of clinical trials being conducted by external pharmaceutical industry sponsors or CROs, whose trials are more likely to resemble Surfaxin in their epistemic aims than, for example, Partners PrEP. ${ }^{29}$ And as argued above, the fixed resources claim is more empirically dubious in the case of industry.

All of this said, however, there is a larger point to be made about the concern for benefits, and that point can be illustrated by highlighting an apparent inconsistency in the defense of liberalism about exploitation. Remember the important assumption that $\mathrm{A}$ is under no obligation to transact with $\mathrm{B}$. If we accept this claim, then it seems strange that a third party, $\mathrm{X}$, would be under some moral obligation to ensure that conditions are optimal so as to encourage A to transact with B. If concern for B's well-being is sufficiently strong so as to dissuade X from interfering with any event which may improve B's well-being, why is that concern not strong enough to compel A to interact with B in ways which will better serve B?

This way of phrasing the problem has intuitive force, but it obfuscates between the duty to aid and the duty to not obstruct benefits which are already on offer. But consider the following: The upshot of the defense of liberalism about exploitation in the context of a fixed quantity of research resources is that we ought not to intervene in an exploitative transaction between $\mathrm{A}$ and $\mathrm{B}$ if, in enforcing less

\footnotetext{
${ }^{29}$ J.M. Baeten, et al. Antiretroviral Prophylaxis for HIV Prevention in Heterosexual Men and Women. $N$ Engl J Med 2012; 367:399-410.
} 
exploitative terms between A and B, we deprive C of the opportunity to be similarly wrongfully (but beneficially) exploited by diverting more resources to B, who is already benefiting at some level from her transaction with A. Now it looks like the liberal about exploitation is defending not just the PEP, but something like the more demanding PEP*: If an otherwise exploitative potential transaction between A and C will serve C's interests, all things considered, if the transaction will not harm anyone external to the transaction, and if $\mathrm{C}$ would make a voluntary, informed, and rational decision to transact with $\mathrm{A}$, then we have an obligation to maximize opportunities for As to so exploit Cs. But surely we do not want to accept PEP*, as it commits us to a moral obligation to promote what we have already conceded are immoral interactions.

This also points to a further tension in the case for non-regulation of international research transactions. Participation in research is generally considered a burden. ${ }^{30}$ In the majority of clinical trials, participants are put at risk of harm usually an unknown level of risk, and often in the context of uncertainty about what kinds of harms. For both this reason, and due to considerations regarding the responsible distribution of research resources, researchers are generally considered ethically obligated to limit sample sizes consistent with good study design so as to minimize the risks and burdens associated with any given study. ${ }^{31}$ Regardless of the importance of the research question, conceiving of clinical trials as a mechanism for gaining access to treatment or providing other social and economic goods to host communities is problematic for a number of reasons: research is, by definition, aimed

\footnotetext{
${ }^{30}$ Although there are exceptions to this, for example when patients are refractory to treatment or suffer high-burden diseases for which there are no known effective interventions.

${ }^{31}$ J.A. Knottnerus and L.M. Bouter. The ethics of sample size: Two-sided testing and one-sided thinking. $J$ Clin Epidemiol 2001; 54:109-110.
} 
at producing socially valuable knowledge, not at providing treatment for patients, and at a minimum there is a tension between the obligations of researchers qua researchers and researchers in their fiduciary role as physicians. ${ }^{32}$ More than this, clinical trials serve an important social, rather than individual, function. Their purpose is to contribute to society’s continued biomedical progress. Conceiving of clinical research as a mere vehicle for delivery of innovative or unproven treatments to participants thus risks subverting the importance of ensuring resources are used to produce socially valuable knowledge. $^{33}$

The same might be said about conceiving of clinical trials as a delivery mechanism for needed social and economic resources. If there was a legitimate complaint about the overall number of clinical trials being reduced, it would have to be that fewer important questions are able to be answered with fewer trials. But this is a different complaint than that levied by liberals about exploitation, which is that fewer trials entail fewer opportunities for communities to benefit from hosting them. Regardless of the benefit to a community from hosting research, however, we would not make the unqualified claim that it is good for communities and their members to participate in as much research as possible, precisely because of the burdens associated with such participation. Thus it is odd to complain that the establishment of mechanisms to ensure a fairer distribution of the social surplus in international research transactions would result in fewer individuals or communities having the opportunity to participate in or host clinical trials. The problem I am here

\footnotetext{
${ }^{32}$ H. Brody and F.G. Miller. The Clinician-Investigator: Unavoidable but Manageable Tension. Kennedy Inst Ethics $J$ 2003; 13:329-346.

${ }^{33}$ A.J. London, J. Kimmelman and M.E. Emborg. Beyond Access vs. Protection in Trials of Innovative Therapies. Science 2010; 328:829-830.
} 
highlighting is the deeper tension in relying on clinical research as a mechanism for delivery of much needed resources to underprivileged communities.

\section{Conclusion}

I have argued that liberals about exploitation in clinical research ground their claims regarding the regulation of international research agreements in the value of autonomy and a concern regarding the benefits accruing to potentially exploited parties. I have demonstrated that a concern for autonomy need not preclude regulatory intervention in, or governance over, international research negotiations: reconceptualizing such negotiations as a type of collective action problem illustrates that regulation of such transactions need not constitute impermissible paternalism, but may actually serve to further the autonomous goals of potential host communities. Moreover, given the large financial incentive to conduct research in LMICs, the concern that restrictions to such transactions will eliminate benefits to potential host communities is overstated. This concern is grounded in two empirical assumptions about which there are good reasons to be skeptical.

This analysis leaves open a host of empirical questions regarding the best and most effective means by which to regulate the outcomes of research transactions so as to both maintain the financial incentive to bring resources to LMIC populations and to ensure that potential host communities are sufficiently empowered to influence the shape and effect of those regulations. I have not sought to show that it is always permissible to intervene in exploitative transactions, but rather to advance the discussion so far as establishing that the fact that a transaction is both mutuallybeneficial and consensual is not an indefeasible basis upon which to ground a duty of 
non-interference, and that there is good ethical and empirical reason to seek evidencebased institutional solutions to ensuring that international research is conducted on fair, or at least fairer, terms. Rather than accepting the unfortunate fact of the status quo and bemoaning that we must continue to allow exploitative interactions for the good of those being exploited, we ought to explore the implications of the policy responses available which could limit or even eliminate such exploitation.

\section{Acknowledgments}

The author would like to thank Derrick F. Gray, Alex John London, and two anonymous reviewers at Developing World Bioethics, as well as audiences at the Cleveland Clinic, Oakland University, and the Association for Political Theory for their valuable feedback on earlier drafts of this manuscript. 